\title{
Perfil epidemiológico e clínico de usuários do centro municipal de referência de indivíduos com doença falciforme em Feira de Santana/Bahia
}

\author{
Epidemiological and Clinical Profile of Users of the Municipal Reference Center for Individuals \\ With Sickle Cell Disease in Feira de Santana/Bahia \\ Perfil Epidemiológico y Clínico de los Usuarios del Centro Municipal de Referencia para Personas \\ con Drepanocitosis en Feira de Santana / Bahia
}

Recebido: 25/05/2021 | Revisado: 01/06/2021 | Aceito: 05/06/2021 | Publicado: 18/06/2021

Ruanna Caribé Ribeiro da Silva ORCID: https://orcid.org/000-0002-3472-2381 Faculdade Anísio Teixeira, Brasil

E-mail: ruannacaribe@ hotmail.com

Suane Pereira de Oliveira Rios Barbosa

ORCID: https://orcid.org/0000-0001-5576-0507 Faculdade Anísio Teixeira, Brasil suaane_rios@hotmail.com

Maria Emília Cirqueira Silva

ORCID: https://orcid.org/0000-0002-8556-482X

Faculdade Anísio Teixeira, Brasil

E-mail: emiliacirqueira@gmail.com

Caroline Ramalho Galvão

ORCID: https://orcid.org/0000-0002-5836-7345

Universidade Estadual de Feira de Santana E-mail: galvaokarol@hotmail.com

Ana Clara Silva Oliveira

ORCID: https://orcid.org/0000-0001-8489-3739

Faculdade Anísio Teixeira, Brasil

E-mail: aclaras_1@outlook.com

Bruna Matos Santos Dantas

ORCID: https://orcid.org/0000-0002-2829-8422

Universidade Estadual de Feira de Santana, Brasil

E-mail: brunamatos.dantas@gmail.com

Lorena Moura de Assis Sampaio

ORCID: https://orcid.org/0000-0003-0627-4494

Universidade Estadual de Feira de Santana, Brasil

E-mail: lorenamoura@fat.edu.br

Maurício Mitsuo da Monção

ORCID: https://orcid.org/0000-0003-0183-1992

Instituto Federal de Educação da Bahia, Brasil

E-mail: maurimitsuo@yahoo.com.br

Magno Conceição das Mercês

ORCID: https://orcid.org/0000-0003-3493-8606

Universidade do Estado da Bahia, Brasil

E-mail: magnomerces@hotmail.com

Sarah dos Santos Conceição

ORCID: https://orcid.org/0000-0001-5729-1249

Universidade de Brasília, Brasil

E-mail: sarahs.conceicao@gmail.com

Roberta Borges Silva

ORCID: https://orcid.org/0000-0001-7273-5151

Ministério da Saúde, Brasil

E-mail: roberta.silva.borges@gmail.com

Lyvia Mirelle Carneiro de França

ORCID: https://orcid.org/ 0000-0003-0844-9833

Secretaria Municipal de Salvador, Brasil E-mail: lyviafranca@hotmail.com

Julita Maria Freitas Coelho

ORCID: https://orcid.org/0000-0002-9520-5177 Instituto Federal da Bahia, Brasil E-mail: julitamaria@gmail.com 


\begin{abstract}
Resumo
A Doença Falciforme (DF) é uma hemoglobinopatia de predominância da hemoglobina $\mathrm{S}$ nas hemácias, de caráter genético. O objetivo deste trabalho foi descrever o perfil epidemiológico e clínico de 64 usuários com DF do Centro Municipal de Referência à pessoa com DF no município de Feira de Santana/BA, no período de novembro de 2016 a março de 2017. O presente estudo foi submetido e aprovado por um comitê de ética em pesquisa. A predominância foi do sexo feminino, raça/cor foi parda/preta, escolaridade menor que 8 anos de estudo, renda menor ou igual um salário mínimo e sem ocupação. Quanto às condições clínicas, a maioria teve diagnóstico médico de anemia falciforme e a descoberta da doença ocorreu via teste do pezinho. Embora a maioria não possuísse comorbidades, um elevado número de participantes apresentou algum tipo de complicação referente à doença, sendo mais frequentes as crises álgicas, pneumonia, síndrome torácica aguda e sequestro esplênico. Os resultados apresentados podem ser usados pelo serviço como instrumento para traçar um plano de cuidado para essa população de acordo com o perfil epidemiológico e clínico dos usuários, bem como, reforça a importância de estratégias como a educação em saúde, para minimizar a ocorrência das complicações.
\end{abstract}

Palavras-chave: Anemia falciforme; Hemoglobina falciforme; Traço falciforme; Epidemiologia.

\begin{abstract}
Sickle cell disease (SCD) is a hemoglobinopathy of predominance of hemoglobin S in red blood cells, of a genetic character. The objective of this study was to describe the epidemiological and clinical profile of 64 users with DF from the Municipal Reference Center for people with DF in the municipality of Feira de Santana / BA, from November 2016 to March 2017. The present study was submitted and approved by a research ethics committee. The predominance was female, race / color was brown / black, education less than 8 years of study, income less than or equal to a minimum wage and without occupation. As for clinical conditions, most had a medical diagnosis of sickle cell anemia and the disease was discovered through the heel prick test. Although the majority did not have comorbidities, a high number of participants presented some type of complication related to the disease, with more frequent pain attacks, pneumonia, acute chest syndrome and splenic sequestration. The results presented can be used by the service as an instrument to outline a care plan for this population according to the epidemiological and clinical profile of users, as well as reinforcing the importance of strategies such as health education, to minimize the occurrence of complications.
\end{abstract}

Keywords: Anemia; Sickle cell; Sickle cell trait; Epidemiology.

\title{
Resumen
}

La anemia de células falciformes (ECF) es una hemoglobinopatía de predominio de la hemoglobina $\mathrm{S}$ en los glóbulos rojos, de carácter genético. El objetivo de este estudio fue describir el perfil epidemiológico y clínico de 64 usuarios con FD del Centro Municipal de Referencia para personas con FD en el municipio de Feira de Santana / BA, de noviembre de 2016 a marzo de 2017. El presente estudio fue presentado y aprobado por un comité de ética en investigación. El predominio fue femenino, raza / color marrón / negro, educación menor a 8 años de estudio, ingreso menor o igual al salario mínimo y sin ocupación. En cuanto a las condiciones clínicas, la mayoría tenía un diagnóstico médico de anemia de células falciformes y la enfermedad se descubrió mediante la prueba de punción del talón. Aunque la mayoría no presentaba comorbilidades, un elevado número de participantes presentó algún tipo de complicación relacionada con la enfermedad, con más frecuentes crisis de dolor, neumonía, síndrome torácico agudo y secuestro esplénico. Los resultados presentados pueden ser utilizados por el servicio como instrumento para delinear un plan de atención a esta población de acuerdo al perfil epidemiológico y clínico de los usuarios, así como reforzar la importancia de estrategias como la educación en salud, para minimizar la ocurrencia de complicaciones.

Palabras clave: Anemia; Drepanocito; El rasgo de células falciformes; Epidemiología.

\section{Introdução}

Considerada como um problema de saúde pública em virtude do elevado número de pessoas vivendo com a patologia, a Doença Falciforme (DF) é uma hemoglobinopatia constituída pela predominância da hemoglobina S (HbS) nas hemácias, de caráter genético e originada de uma mutação no cromossomo 11, responsável pela substituição do ácido glutâmico pela valina. A DF é constituída pelos seguintes tipos: Anemia Falciforme (AF), o tipo mais grave, quando apresenta dois genes de hemoglobina $\mathrm{S}$ (SS); a $\mathrm{S} \beta$ talassemia (S $\beta$ tal.), combinação do gene da hemoglobina $\mathrm{S}$ com o da talessemia $\beta$; ou com outros tipos de hemoglobina como a B, C, E e Alfa Talassemia, resultando nas doenças SC, SD, SE, S $\alpha$-talassemia (Magalhães, Turcato, Ângulo \& Maciel, 2009; Edelstein, 1996).

No entanto, somente uma pequena parte da sua alta variabilidade clínica pode ser explicada pelos marcadores $\mathrm{Hb}$ fetal e a co-herança da $\alpha$-talassemia, particularmente a fenótipos mais leves. A HbS pode se polimerizar, formar hastes rígidas dentro 
da célula vermelha, mudando-a para a forma de uma foice, a falcização, perdendo sua flexibilidade, o que dificulta seu transporte pelos vãos sanguíneos, gerando uma diminuição da oferta de oxigênio nas células e órgãos, vaso-oclusão e a hemólise. Logo, tais danos na hemácia, resultam em um menor tempo de circulação, culminando em quadros de anemia crônica (Kato et al, 2017; Soares et al, 2014).

A vaso-oclusão envolve tanto o fenômeno da falcização quanto uma maior interação entre células endoteliais, leucócitos e plaquetas, vasculopatia proliferativa, estado inflamatório crônico e hipercoagulabilidade. Quando na AF, tal ocorrência resulta em sintomas como crises de dores intensas, além de cansaço, palidez, mucosa dos olhos amarelada, as quais se apresentam de forma intermitente. Dentre as complicações associadas à referida vaso-oclusão, destacam-se a Síndrome Torácica Aguda (STA), a Insuficiência Renal (IR) e o Acidente Vascular Cerebral (AVC). Em suma, tais condições possibilitam uma redução de 25 a 30 anos da expectativa de vida em pacientes acometidos por DF (Brunetta et al, 2010; Brasil, 2010).

As crises de vaso-oclusão ou crises falcêmicas, geralmente as primeiras e mais frequentes manifestações da DF, ocasionam dores musculares, articulares e ósseas causadas por oclusão na microcirculação. Podem ser espontâneas ou desencadeadas por situações estressoras, a exemplo de infecções, e se estendem por quatro a seis dias, mas podendo se prolongar por semanas. Em crianças, a primeira manifestação mais frequente é a dactalite, denominada síndrome do pé-mão, embora possa ocorrer pneumonia e dor abdominal. Em geral, a dor abdominal pode simular abdome agudo cirúrgico ou infeccioso, além de processos ginecológicos (Brunetta et al, 2010; UFRGS, 2020).

Estima-se que a distribuição de pessoas com $\mathrm{HbS}$ vem aumentando anualmente, e a maior prevalência tem sido relatada na África Sub-sesariana, com 50 a 90\% das crianças acometidas (Grosse et al, 2011). No Brasil, estima-se uma prevalência entre 60.000 a 100.000 casos. Além disso, estudos têm mostrado uma maior frequência de DF nas regiões norte e nordeste do Brasil, $6 \%$ a $10 \%$ da população regional, e tal fato justifica-se em virtude do quantitativo de negros e/ou descendentes nestas regiões. Inclusive na Bahia, a doença pode atingir um em cada 650 nascidos vivos (UFRGS, 2010; Cançado, Jesus, 2007; Martins, Moraes - Souza \& Silveira, 2010).

Diante do exposto, estudos como este favorecem o embasamento de profissionais de saúde que prestam assistência aos portadores de DF, com vistas a maior efetividade da assistência, bem como fornece subsídios para estudos subsequentes. Do mesmo modo, informações adicionais acerca da DF tanto por parte dos pacientes e seus familiares, quanto da sociedade acadêmica e pessoas em geral, podem ser úteis na promoção de qualidade de vida aos portadores de DF. Portanto, o objetivo desse estudo foi descrever o perfil epidemiológico e clínico de usuários de um Centro Municipal de Referência à pessoa com DF.

\section{Método}

Foi realizado um estudo descritivo, documental, com abordagem quantitativa, caráter descritivo e exploratório (Estrela, 2018; Pereira et al., 2018; Koche, 2011; Ludke \& André, 2013; Yin, 2015) no Centro Municipal de Referência à pessoa com DF, localizado na Unidade Básica de Saúde (UBS) do Centro Social Urbano (CSU) no município de Feira de Santana - BA. A amostra do estudo foi composta por 64 pacientes que buscaram atendimento no centro de referência no período de novembro de 2016 a março de 2017, de acordo com o calendário de atendimento do serviço.

Os participantes da pesquisa responderam um questionário contendo seis blocos de perguntas referentes a: identificação; aspectos sociodemográficos (escolaridade, renda, ocupação, estado civil e moradia); hábitos de vida (uso de álcool e/ou tabaco e realização de exercícios físicos); história clínica da DF e condições clínicas. Além disso, foram realizadas consultas aos prontuários para obtenção de informações complementares, tais como medicamentos utilizados e histórico de complicações e comorbidades. 
Os dados obtidos foram digitados, processados e categorizados utilizando o programa SPSS 17.0 for Windowns Statistical Package for Social Science 2000 e STATA versão 11.0. Para a análise descritiva proposta foi calculada frequência simples e relativa das categorias consideradas de maior relevância. Os resultados obtidos a partir da distribuição das variáveis do estudo foram apresentados com emprego de tabelas e/ou gráficos.

O presente estudo foi aprovado pelo Comitê de Ética em Pesquisa da Faculdade Anísio Teixeira (CEP-FAT) através do parecer $n^{\circ}$ 1.714.349. Destaca-se que a participação dos indivíduos avaliados foi voluntária, facultativa e sua desistência era permitida em qualquer momento do estudo, respeitando os direitos de autonomia, privacidade e confidencialidade. A concordância em participar do estudo ocorreu mediante processo de consentimento através da assinatura do Termo de Consentimento Livre e Esclarecido (TCLE) e do Termo de Assentimento Livre e Esclarecido (TALE) para pacientes menores de 18 anos.

\section{Resultados}

Dos 64 indivíduos participantes, a maior parte era do sexo feminino, na faixa etária de 0 a 16 anos, e com raça/cor da pele autorreferida parda e/ou preta. A escolaridade foi mais baixa, bem como a menor renda e quantidade de indivíduos sem ocupação. Quanto à densidade domiciliar, predominou coabitação de até quatro moradores/domicílio. Da mesma forma, a maior parte referiu não possuir companheiro. A maioria dos participantes morava em zona urbana, possuía rede de esgoto, e não tinha filhos. Grande parte da amostra referiu não consumir álcool e tabaco, e não realizava atividade física (Tabela 1).

Em relação ao tipo de doença falciforme, a $\mathrm{AF}$ foi o tipo mais prevalente no sexo masculino, enquanto nas mulheres outras DF prevaleceram. Quanto ao método de diagnóstico, na Tabela 1, pode-se observar que o teste do pezinho foi o mais frequente, tanto em homens quanto em mulheres. 
Tabela 1 - Características sociodemográficas e de estilo de vida e tipos de DF de usuários de um Centro Municipal de Referência no período de novembro de 2016 a março de 2017 (n=64). Feira de Santana, BA, Brasil, 2017.

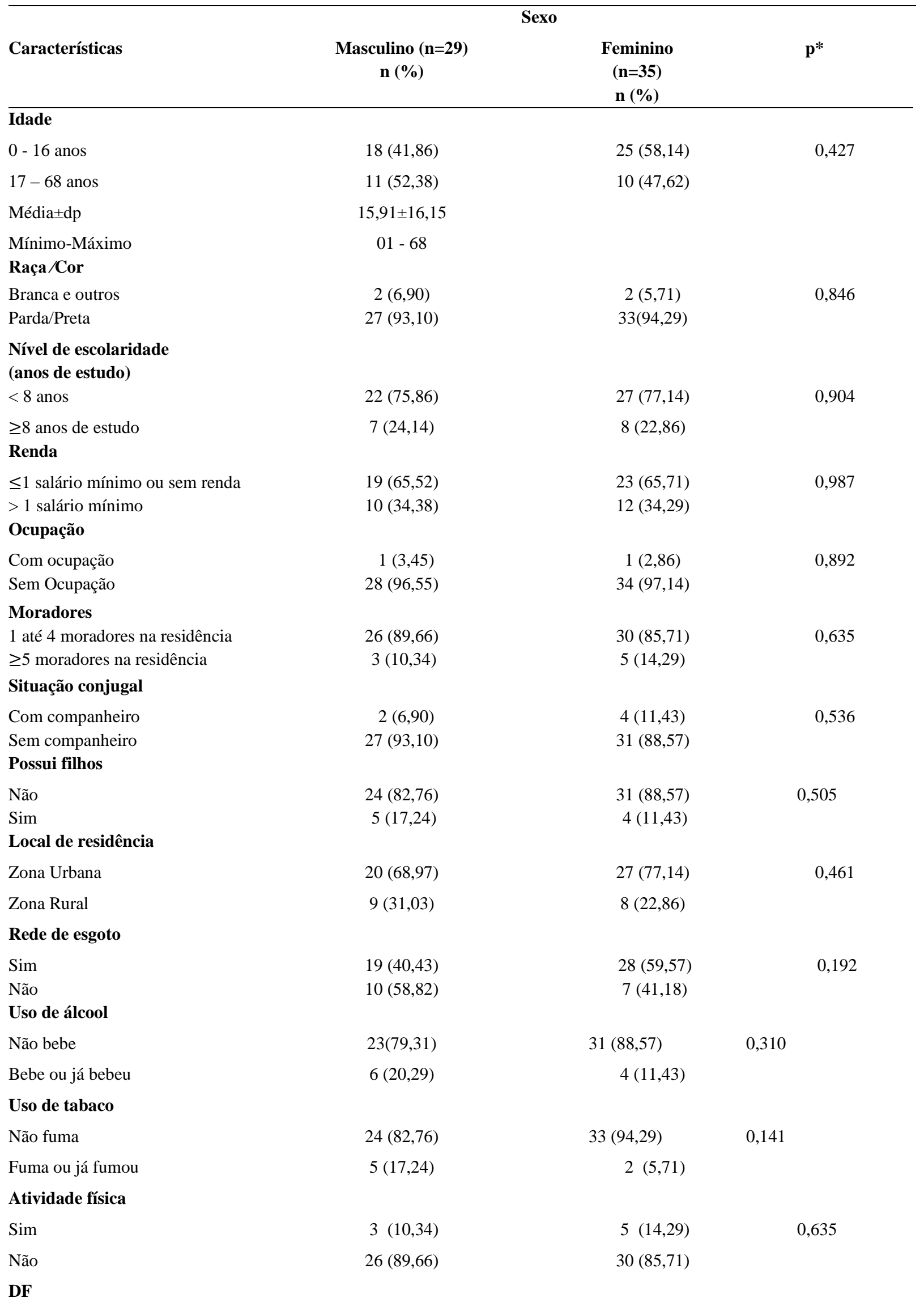




\begin{tabular}{|c|c|c|c|}
\hline$\overline{\mathrm{AF}}$ & $22(75,86)$ & $15(42,86)$ & $0,008^{*}$ \\
\hline Outras Doenças Falciformes & $7(24,14)$ & $20(57,14)$ & \\
\hline \multicolumn{4}{|c|}{ Diagnóstico por Teste do Pezinho } \\
\hline Sim & $20(68,97)$ & $26(74,29)$ & 0,637 \\
\hline Não & $9(31,03)$ & $9(25,71)$ & \\
\hline
\end{tabular}

* Nível de significância estatística: $\mathrm{p} \leq 0,05$

Fonte: Pesquisa de Campo (2016-2017).

Conforme apresentado na Tabela 2, dos 64 pacientes entrevistados, os homens apresentaram maiores históricos de internações. Quanto às complicações, novamente os indivíduos do sexo masculino referiram ter tido no mínimo uma complicação. Quanto ao uso de medicamento para tratamento da DF, a utilização da hydroxiureia e penveoral, apesar de ainda pequena, foi maior no sexo masculino. Em relação ao consumo do deferasirox, ambos os sexos relataram um menor consumo do medicamento. Não houve relato da utilização simultânea das três medicações nos indivíduos investigados.

Tabela 2 - Uso de medicações (hydroxiureia, penveoral e deferasirox), número de internações, complicações e comorbidades relacionadas à DF em usuários de um Centro Municipal de Referência no período de novembro de 2016 a março de 2017 (n=64). Feira de Santana, BA, Brasil, 2017.

\begin{tabular}{|c|c|c|c|c|c|}
\hline \multirow{3}{*}{ Características } & \multicolumn{4}{|c|}{ Sexo } & \multirow{3}{*}{$\mathbf{p}^{*}$} \\
\hline & \multicolumn{2}{|c|}{$\begin{array}{c}\text { Masculino } \\
(\mathbf{n}=29)\end{array}$} & \multicolumn{2}{|c|}{$\begin{array}{c}\text { Feminino } \\
(\mathbf{n}=35)\end{array}$} & \\
\hline & $\underset{\mathbf{n}(\%)}{\operatorname{Sim}}$ & $\begin{array}{c}\text { Não } \\
\text { n (\%) }\end{array}$ & $\underset{n(\%)}{\operatorname{Sim}}$ & $\begin{array}{c}\text { Não } \\
\text { n(\%) }\end{array}$ & \\
\hline $\mathrm{N}^{0}$ de internações & $24(82,76)$ & $5(17,24)$ & $28(80,00)$ & $7(20,00)$ & 0,778 \\
\hline $\mathbf{N}^{0}$ de complicações & $22(75,86)$ & $07(24,14)$ & $21(60,00)$ & $14(40,00)$ & 0,179 \\
\hline $\mathrm{N}^{\circ}$ de comorbidades & $17(58,62)$ & $12(41,38)$ & $12(34,29)$ & $23(65,71)$ & 0,052 \\
\hline Uso de hydroxiureia & $9(31,03)$ & $20(68,97)$ & $3(8,57)$ & $32(91,43)$ & $0,022 *$ \\
\hline Uso de penveoral & $9(31,03)$ & $20(68,97)$ & $7(20,00)$ & $28(80,00)$ & 0,310 \\
\hline Uso de deferasirox $* *$ & $2(6,90)$ & $27(93,10)$ & $2(5,71)$ & $33(94,29)$ & - \\
\hline $\begin{array}{l}\text { Não uso de hydroxiureia/ } \\
\text { penveoral/ deferasirox** }\end{array}$ & - & $29(\%)$ & - & $35(\%)$ & - \\
\hline
\end{tabular}

*Nível de significância estatística: $\mathrm{p} \leq 0,05$

** Marca Exjade

Fonte: Pesquisa de Campo (2016-2017).

No que se refere ao tipo de complicações, prevaleceram as crises álgicas, tanto em homens, quanto em mulheres, seguido de pneumonia, STA e sequestro esplênico. Também foram citados casos de dactalite, litíase, osteomielite, derrame pleural, priapismo e AVC. 
Gráfico 1 - Usuários com presença de complicações relacionadas à DF na amostra no período de novembro de 2016 a março de 2017 (n=64). Feira de Santana, BA, Brasil, 2017.

\section{ENTREVISTADOS COM PRESENÇA DE COMPLICAÇÕES}

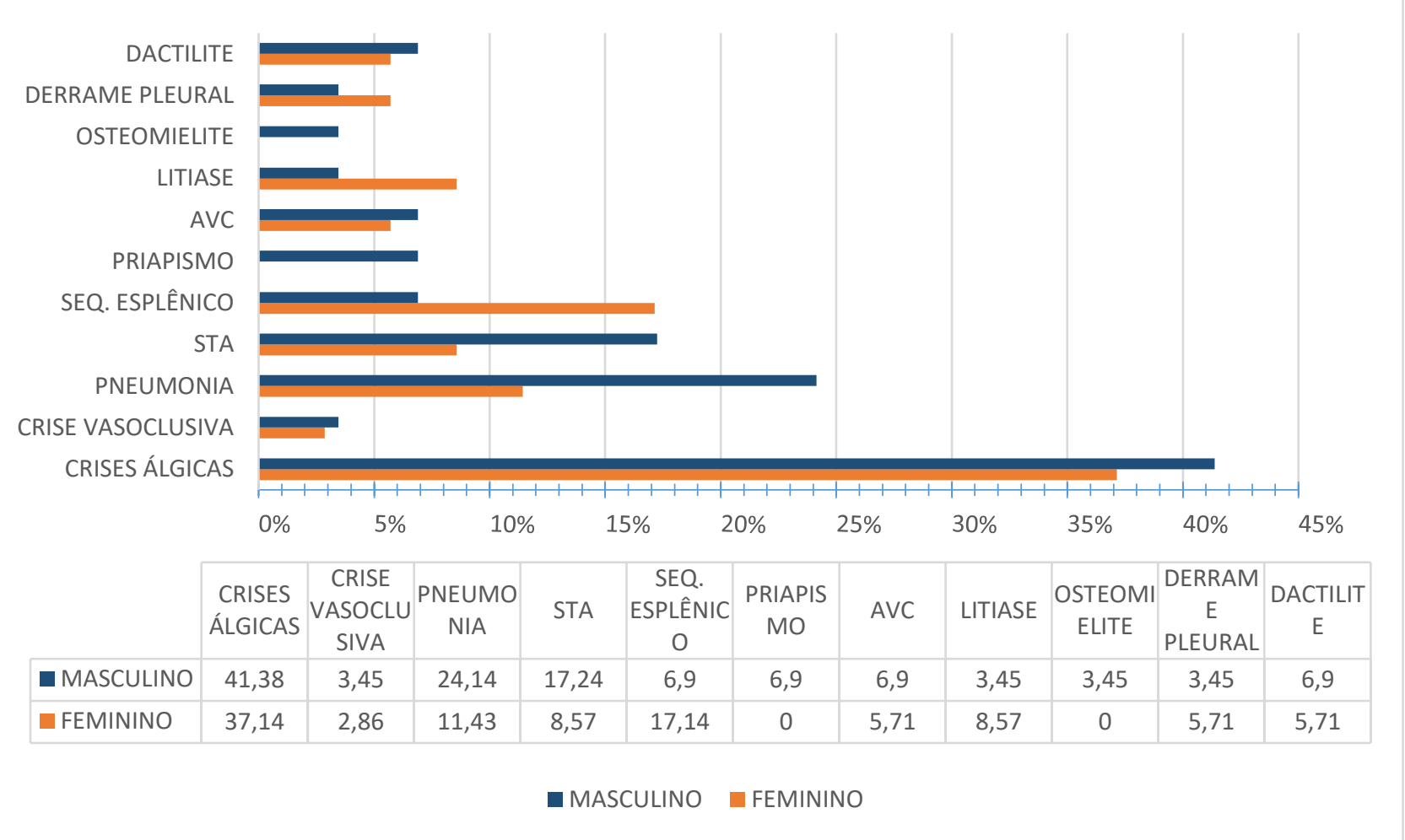

Fonte: Pesquisa de Campo (2016-2017).

\section{Resultados e Discussão}

De uma forma geral houve uma maior prevalência de AF nos homens em comparação com as mulheres, e histórico de vários eventos de internações e complicações. Contrariando os achados de Felix, Souza e Ribeiro (2010) que demonstraram uma maior prevalência de AF no sexo feminino (59,6\%), assim como Amaral, Almeida, Santos, Oliveira e Lanza (2015), que também verificaram uma maior prevalência feminina (55\%) em estudo em Minas Gerais. Os resultados do presente estudo são semelhantes aos encontrados na literatura por Carvalho et al. (2020), e podem ser justificados pela amostra reduzida ou em decorrência da baixa adesão dos homens aos serviços de saúde, como comprovado por Gomes, Nascimento e Araújo (2007).

Como também foi demonstrado no presente estudo em relação à raça/cor, a literatura aponta a predominância de DF em indivíduos pardos e/ou pretos. Historicamente, em decorrência da associação ao período colonial e ao processo de escravidão, vários autores relacionam a prevalência de DF na população negra (Felix et al, 2015; Amaral et al, 2015; Almeida, Camargo e Felzemburgh, 2012; Brasil, 2015). Além disso, Boulet, Yanni, Creary e Olney (2010) evidenciam negros como grupo de risco ao comparar crianças negras com e sem DF, afirmando que crianças negras com DF são, frequentemente, mais propensas a dores de cabeça ou enxaquecas, deficiência intelectual, necessidade de fazer uso regular de medicamentos, e a condições de saúde regular ou ruim.

Analisando características econômicas familiares dos indivíduos com DF, os autores Marques, Souza e Pereira (2015) relataram uma renda mensal média de dois salários mínimos, com cerca de seis moradores por residência. Ainda, foi descrito por Felix, Souza e Ribeiro (2010) um total de 74,4\% de entrevistados sem renda, com renda até 1 salário mínimo ou que tenham bolsa auxilio, e quanto a escolaridade, esses autores descreveram que 42,5\% dos pacientes tinham escolaridade igual ou superior 
ao ensino médio completo e apenas 6,4\% não frequentaram a escola. O maior percentual encontrado neste estudo de entrevistados com renda menor ou igual a um salário mínimo, e com menos de 8 anos de estudos pode estar relacionado a faixa etária dos participantes. Essa condição é considerada alarmante, pois segundo demonstrado por Palermo et al. (2002), a situação socioeconômica dos indivíduos acometidos por DF seria um preditor significativo de incapacidade funcional.

Os dados encontrados neste estudo acerca da baixa escolaridade e do nível socioeconômico dos pacientes foram semelhantes à estudos realizados na Inglaterra, (Aljuburi et al, 2013) nos Estados Unidos da América (McCavit et al, 2011), na Nigéria (Adegoke et al, 2015) e em outros Estados do Brasil (Feliz et al, 2010; Pereira et al, 2008; Loureiro et al, 2005). Tal situação permite destacar que, o alto custo dos medicamentos para terapia de DF somado ao menor nível socioeconômico dos pacientes, os conduz a uma dependência dos programas públicos de dispensa de medicamentos. Ressalta-se que a vulnerabilidade social impacta na qualidade de vida dos indivíduos, mantendo-os dependentes em um ciclo vicioso de programas governamentais de benefícios financeiros e de saúde.

Portanto, os indivíduos em situação socioeconômica vulnerável merecem atenção especial no que diz respeito às perspectivas médica e psicossocial, visto estarem mais expostos aos fatores sociais determinantes da DF (Paiva e Silva et al, 1993). Essa condição é relatada por Ghafuri et al. (2020) ao sinalizarem a necessidade de recursos para tratamento e gerenciamento da desnutrição em crianças nigerianas com AF. Assim, é possível inferir que a mesma necessidade pode ser atribuída às crianças brasileiras, visto que a desnutrição, apesar de cada vez menor, ainda é um problema social relevante no país.

Neste estudo, a maioria dos participantes ora investigados se encontravam na faixa etária de até 43 anos de idade, e esse predomínio de DF em pessoas mais jovens pode reafirmar a gravidade da doença, considerando a baixa expectativa de vida dos pacientes. De tal maneira, o diagnóstico precoce e a realização de intervenções específicas permitirão, além de reduzir os danos físicos, a adoção de estratégias mais proativas frente às limitações impostas pela doença (Carvalho et al, 2020). Além disso, Amaral et al. (2015), enfatizaram a expectativa média de vida dos acometidos por DF que, no país, é de 48 anos, mediante a essa informação a gravidade de complicações advindas da doença falcêmica, é inversamente proporcional a expectativa de vida.

Nesse sentido, os autores Thein e Howard (2018) alertam para a maior susceptibilidade de idosos acometidos com DF, uma vez que podem desenvolver outros agravos associados à idade que interferem aumentando a morbidade da doença. Ainda, esses autores pontuam que as comorbidades tratáveis e deterioração aguda devem ser tratadas agressivamente, para melhoria da DF e a minimização de danos a órgãos, e por isso sugerem maior proatividade na inclusão de terapias curativas, antes somente ofertadas ao paciente jovem, bem como aquelas de caráter experimental em tempo hábil.

Assim como observado no presente estudo, Felix, Souza e Ribeiro (2010) também identificaram baixa adesão ao tabaco e às bebidas alcóolicas nos indivíduos investigados, e tal situação é relevante, considerando que o uso abusivo dessas drogas lícitas pode provocar danos adicionais a saúde, como câncer e cirrose hepática. Não foram encontrados dados na literatura sobre a prática de atividade física pelos pacientes com DF, e apesar dessa prática ser benéfica por minimizar a ocorrência de doenças cardiovasculares, e evitar complicações sérias, como o AVC, uma pequena parcela dos participantes deste estudo realizaram alguma atividade física.

Os achados da presente investigação a respeito do diagnóstico médico de AF estão em conformidade com o encontrado na literatura, apresentando homozigose da hemoglobina S, condição também verificada por Menezes et al. (2013) em crianças brasileiras no estado de São Paulo. Sabe-se que esse tipo de DF é considerada o genótipo mais grave, geralmente associada à baixa expectativa de vida (Felix et al, 2010; Amaral et al, 2015; Paiva e Silva et al, 1993).

Sob este prisma, neste estudo a AF predominou no sexo masculino, enquanto nas mulheres prevaleceram outras doenças falciformes mais raras, contudo, no estudo de Menezes et al. (2013) verificou-se maior prevalência de AF no sexo feminino entre 
crianças. Ainda, ressalta-se que tais resultados não foram discutidos anteriormente por outros autores, porém essas prevalências podem ser justificadas em decorrência do pequeno tamanho da amostra empregada.

Outra variável relevante analisada por esta pesquisa foi o método de diagnóstico da doença, corroborando os achados de Felix, Souza e Ribeiro (2010) e Amaral et al. (2015), em que a maioria dos participantes teve a descoberta da DF através do teste do pezinho. Na compreensão dos autores Leão e Aguiar (2008), o diagnóstico precoce de DF possibilita grandes benefícios ao paciente, como a profilaxia de infecções, imunizações, educação da família para identificação e procura de tratamento rápido para as principais complicações, o que contribui para a redução da morbidade e mortalidade, tendo como objetivo final o incremento da qualidade de vida dessa população.

No Brasil, a DF é a doença genética de maior incidência e nascem cerca de 3500 crianças por ano com DF, com um recém-nascido com DF em cada 1000 nascimentos, e na capital Baiana, Salvador, nasce um recém-nascido em cada 650 nascidos vivos, média de 65 crianças com DF por ano (Salvador, 2019). Esses números reforçam a necessidade do diagnóstico precoce, acompanhamento regular com equipe de saúde, além de suporte social como forma de reduzir e até evitar os agravos e complicações da doença.

Como propõe Piel et al. (2013), a vasta implementação de intervenções acessíveis, incluindo diagnóstico neonatal e profilaxia com penicilina, seria capaz de prolongar a vida de cerca de 5 milhões de bebês recém-nascidos com AF em 2050. Nesta lógica, programas de triagem e tratamento em grande escala poderiam salvar até 10 milhões de recém-nascidos com AF em todo o mundo, em especial na África Subsaariana, dada sua mais alta prevalência (Piel et al, 2013; Williams et al, 2009). Logo, é possível reafirmar que a implementação de programas universais de triagem neonatal continua sendo um grande desafio econômico e de saúde pública (Kato et al, 2017).

Assim como no estudo de Felix, Souza e Ribeiro (2010), 29 usuários desta pesquisa apresentaram comorbidades associadas à DF, sendo mais frequentes as alterações do sistema cardiovascular como as cardiopatias e hipertensão arterial, ou doenças pulmonares. Os autores Martins e Teixeira (2017) afirmam que a DF é evolutiva em complicações agudas para diferentes faixas etárias, caracterizando a maioria das internações em atendimento de urgência, o que pode ser observado na amostra do atual estudo uma vez que 43 usuários ( 22 do sexo masculino e 21 do sexo feminino) progrediram para situações emergenciais.

Sabe-se que manifestação da dor é causada por oclusão microvascular com subsequente lesão do tecido em resposta aos glóbulos vermelhos (Carvalho et al, 2020), e segundo Brunetta et al. (2010), a crise álgica ou Crise Vaso-Oclusiva (CVO) representa o quadro de dor que é instalado no indivíduo com DF. No atual estudo, a crise álgica também foi o sintoma mais observado em pessoas com DF, condizendo com outros estudos (Boulet et al, 2010; Menezes et al, 2013) que detectaram alta frequência desse sintoma.

Furtado, Motta e Santos (2015) observaram que a crise álgica foi um sintoma presente em 86,7\% dos indivíduos investigados. Segundo Amaral et al. (2015), os episódios agudos de dor ou as CVO são uma marca registrada da DF, e progridem a ser um marcador para a gravidade da DF e mortalidade prematura. De acordo com Martins e Teixeira (2017), essa crise é a causa mais comum de internação e não possui prevenção específica, somente a utilização do medicamento hidroxiureia pode auxiliar na diminuição da frequência de crises. Ainda nesse quesito, Loureiro e Rozenfeld (2005) descreveram que a crise pode ser resolvida em média em cinco dias. De uma forma geral, é necessária uma capacitação permanente de profissionais de serviços de atenção a pessoas com DF para o pronto atendimento de demandas por crises álgicas, considerando o bem-estar dos usuários e sua garantia de qualidade de vida.

Quanto as infecções, principal causa de morte em poucas horas na DF, segundo os autores Brunetta et al. (2010), o tipo mais comum é a pneumonia, com maior incidência em crianças. Os autores apontam que o risco de septicemia e/ou meningite por Streptococcus pneumoniae ou Haemophilus influenzae chega a ser 600 vezes maior do que em crianças sem DF. Destaca-se 
que, no presente estudo, foi encontrada uma frequência maior dessa infecção em usuários masculinos. Isso denota reflexões por parte do serviço acerca do controle de infecções nesses usuários.

Segundo os achados de Fernandes et al. (2015), 38,5 \% dos óbitos no seu estudo foram atribuídos às infecções, configurando como a maior causa, seguida de sequestro esplênico (16,6\%). Esses dados ascendem à necessidade de monitoramento criterioso de infecções em pacientes com DF, bem como educação permanente de usuários quanto à prevenção de tais complicações. Nesse sentido, destaca-se um maior risco às infecções do grupo em estudo, visto que parte dos indivíduos residiam em locais sem esgotamento sanitário $(26,56 \%)$.

Por sua vez, a STA é descrita na literatura (Brunetta et al, 2010) como a segunda causa de hospitalização e possui maior frequência de internações em centros de terapias intensivas, podendo evoluir como causa principal para o quadro de mortalidade precoce em falciformes. Sabe-se que a STA pode ser causada por infecções, embolia de medula óssea necrótica, vaso-oclusão pulmonar e sequestro pulmonar, envolvendo infiltrado pulmonar associado a dor torácica, tosse, dispneia, taquipneia ou outros, além da queda dos níveis de oxigenação no sangue (Oliveira et al, 2020). Os valores encontrados para STA neste estudo condizem com a literatura, sendo duas vezes mais frequentes em homens.

Ainda na compreensão dos autores Brunetta et al. (2010), o sequestro esplênico é uma complicação muito frequente em pacientes falcêmicos, principalmente na infância, contudo pode ocorrer em adultos, com prevalência maior em hemoglobinopatias SC. Além disso, Amaral et al. (2015), ratificam que em algum momento da vida seus pacientes sofreram esta complicação. Os dados ora identificados demonstram que uma taxa relativa dos participantes já passou por esta situação. Salienta-se que a esplenectomia, de urgência ou eletiva, deve ser indicada após recuperação do sequestro esplênico, apontando para cuidados específicos no grupo ora investigado (Brunetta et al, 2010).

A literatura descreve um valor de 2 a $6 \%$ para priaprismo como complicação da DF, e o aprisionamento das hemácias falcizadas no corpo cavernoso tem mostrado uma incidência de até $100 \%$ dos pacientes do sexo masculino (Lottenberg \& Hanssell, 2005). Vale destacar que, como afirmam Amaral et al. (2015), os adultos com DF e histórico desta complicação possuem cinco vezes mais risco em desenvolver hipertensão pulmonar. No presente estudo, cerca de $6 \%$ de frequência de priapismo foi detectada, o que sugere necessidade de monitoração desse agravo não somente pelo desconforto, mas pela possibilidade de complicações mais graves como a hipertensão.

O AVC é uma complicação grave que ocorre em ambos os sexos, em qualquer faixa etária (Brunetta et al, 2010), e tem sido imputado como o responsável mais comum por lesão neurológica permanente em crianças, e em adultos com talassemia HbSS e HbSb0 (Bernaudin et al, 2015; Kassim et al, 2016). Ressalta-se que em pacientes de 02 a 16 anos de idade, a American Society of Hematogy (ASH) recomenda a realização anual de ultrassom doppler transcraniano, no entanto, referente às diretrizes para a prevenção, triagem e tratamento de suas manifestações no sistema nervoso central, a ASH descreve a prática como escassa (DeBaun et al, 2020).

Sabe-se que o AVC isquêmico de grande artéria é consequência da hemólise típica da AF, bem como da disfunção vasomotora, vasculopatia proliferativa e de complicações clínicas da vasculopatia pulmonar e sistêmica, incluindo hipertensão pulmonar, úlceras de perna, priapismo e doença renal crônica. Tais consequências decorrem da liberação de hemoglobina descompartimentada, arginase 1, dimetilarginina assimétrica e nucleotídeos de adenina, produtos da referida hemólise (Kato et al, 2017). Todavia, no presente estudo foram encontrados poucos casos de AVC, e sem diferenças entre os sexos, gravidade, ações preventivas e manejo.

Neste estudo, o histórico de litíase biliar foi relatado por 3,45\% de homens que já tiveram essa complicação e 8,57\% das mulheres entrevistadas, mas não foi comprovado a ocorrência de intervenção cirúrgica. No entanto, Moerdler \& Manwani (2018), pontuam que a lesão de isquemia-reperfusão, hemólise e dano oxidativo aumentam a inflamação e ativam o sistema 
hemostático. Logo, entende-se que tais vias têm sido consideradas como tratamentos emergentes potenciais para melhorar as manifestações DF.

Para os autores Brunetta et al. (2010), a osteomielite é outra complicação infecciosa persistente com prevalência descrita em até $12 \%$ dos pacientes falciformes. Entretanto, no estudo atual, somente 3,45\% de homens mencionaram positivamente a complicação, podendo ser justificado pelo tamanho da amostra. No tocante à ocorrência de derrame pleural, foi notada uma baixa ocorrência na amostra (3,45\% homens e 5,71\% mulheres), contudo, não foram encontrados dados na literatura referente a tal complicação em outras pesquisas.

No entendimento de Amaral et al. (2015), o mecanismo desencadeante da dor do paciente falcêmico é sempre complexo e provavelmente heterogêneo, dependente da região afetada. Desta maneira, a dor em caso de dactilite corresponde a um processo inflamatório iniciado por necrose da medula óssea nas porções distais dos membros, e no presente estudo foram detectadas diferenças significativas para essa complicação inflamatória.

A inflamação é considerada como fator chave na propagação e exacerbação da lesão tecidual causada por AF (Moerdler et al, 2018). Os autores afirmam que todos os componentes celulares do sistema imunológico, incluindo neutrófilos, linfócitos, monócitos e plaquetas, possam contribuir para tal processo, e que muitas citocinas pró-inflamatórias são cronicamente ou tornamse agudamente elevadas na DF. Domingos et al. (2020) relataram uma associação forte entre altos níveis de interleucina 6 e a piora dos pacientes com DF, apresentando quadros de STA, úlceras de perna, osteonecrose, AVC e priapismo a inflamação. Ou seja, diversas abordagens de tratamento anti-inflamatório podem ser pensadas para o tratamento da doença.

A DF é reconhecida pela Organização Mundial de Saúde como um problema global de saúde pública, e espera-se um número total de 14,24 milhões de bebês nascidos com a doença entre 2010 e 2050 (Piel et al, 2013). Considerando que os dados do Ministério da Saúde no Brasil estimam que cerca de 3,5 mil crianças nascem com AF a cada ano, com 25 mil a 30 mil casos de DF (Cançado et al, 2007), torna-se indispensável o aprimoramento de políticas públicas que proporcionem aos brasileiros com DF melhor acesso ao tratamento médico, condições de vida e integração à sociedade (Fernandes et al, 2015). Apesar disso, a não padronização das informações nos prontuários e o pequeno tamanho da amostra tornaram árdua a coleta de dados deste estudo, bem como a baixa adesão dos pacientes com DF à pesquisa.

\section{Considerações Finais}

A DF reflete de maneira negativa na qualidade de vida dos indivíduos acometidos, dificultando a execução de atividades diárias/laborais, bem como prejudicando à vida social, uma vez que as complicações apresentadas permitem que os pacientes se sintam incapazes. O árduo enfrentamento dessa patologia, somado ao desemprego, a má remuneração ou até mesmo a ausência do auxílio doença, poderia ser amenizado com o acompanhamento social e psicoterápico.

Os resultados deste estudo permitiram conhecer o perfil epidemiológico de indivíduos com DF, retratando a predominância de mulheres jovens, pardas e/ou pretas, com baixa condição socioeconômica, sem ocupação, sem companheiro e/ou filhos, residentes em zona urbana e não praticantes de atividade física. Mesmo sem comorbidades, um elevado número de participantes relata complicação referente da DF, especialmente crises álgicas, pneumonia, STA e sequestro esplênico. Tais resultados podem auxiliar no planejamento técnico de cuidado para essa população de acordo com o perfil epidemiológico e clínico encontrado, promovendo educação em saúde, trazendo informações que minimizam a ocorrência das complicações e também propiciando ao enfermeiro um planejamento do cuidado com um acompanhamento da equipe multiprofissional.

Diante dos resultados mencionados anteriormente, é importante que o presente estudo gere a realização de mais pesquisas, afim de que estas possam ampliar ainda mais o conhecimento acerca da patologia em questão, a doença falciforme. 


\section{Referências}

Aljuburi, G., Laverty, A. A., Green, S. A., Phekoo, K. J., Bell, D., \& Majeed, A. (2013). Socio-economic deprivation and risk of emergency readmission and inpatient mortality in people with sickle cell disease in England: Observational study. J Public Heal (United Kingdom). 35(4):510-7. https://pubmed.ncbi.nlm.nih.gov/24169414/

Adegoke, S. A., Adeodu, O. O., \& Adekile, A. D. (2015). Sickle cell disease clinical phenotypes in children from South-Western, Nigeria. Niger J Clin Pract. 18(1):95-101. https://pubmed.ncbi.nlm.nih.gov/25511352/

Almeida, T. M. C., Camargo, C. L., \& Felzemburgh, R. D. M. (2012). Crianças com doença falciforme: um estudo descritivo. Online Brazilian J Nurs. 11(3):76377. http://www.objnursing.uff.br/index.php/nursing/article/download/3823/pdf

Amaral, J. L., Almeida, N. A., Santos, P. S., de Oliveira, P. P., \& Lanza, F. M. (2015). Socio-demographic, economic and health profile of adults with sicklecell disease. Rev da Rede Enferm do Nord. 16(3):296-305. https://www.redalyc.org/pdf/3240/324041234002.pdf

Brasil. (2013). Lei Municipal $n^{o}$ 3412/2013. https://leismunicipais.com.br/a/ba/f/feira-de-santana/lei-ordinaria/2013/342/3412/lei-ordinaria-n-3412-2013-dispoesobre-a-criacao-do-programa-e-atencao-integral-as-doencas-falciformes-no-ambito-do-municipio-de-feira-de-santana-e-da-outras-providencias

Brasil. (2006). Ministério da Saúde. Manual de condutas básicas na doença falciforme. Secretaria de Atenção à Saúde. Departamento de Atenção Especializada: Editora do Ministério da Saúde, 56. http://www.riocomsaude.rj.gov.br/Publico/MostrarArquivo.aspx?C=Y0\%2BU19IsUXc\%3D

Brasil, M da S. (2015). Doença Falciforme: conhecer para cuidar. Secretaria de Vigilância em Saúde Coordenação Geral de Sangue e Hemoderivados. https://telelab.aids.gov.br/moodle/pluginfile.php/39506/mod_resource/content/4/Doenca\%20Falciforme_SEM.pdf.

Bernaudin, F., Verlhac, S., Arnaud, C., Kamdem, A., Vasile, M., Kasbi, F. et al. (2015). Chronic acute anemia and extracranial internal carotid stenosis are risk factors for silent cerebral infarcts in sickle cell anemia. Blood. 125(10):1653-61. https://pubmed.ncbi.nlm.nih.gov/25533032/

Boulet, S. L., Yanni, E. A., Creary, M. S., \& Olney, R. S. (2010). Health Status and Healthcare Use in a National Sample of Children with Sickle Cell Disease. Am J Prev Med. 38(4 SUPPL.):S528-35. https://pubmed.ncbi.nlm.nih.gov/20331954/

Brunetta, D. M., Clé, D. V., Haes, T. M., Roriz-Filho, J. S., \& Moriguti, J. C. (2010). Manejo das complicações agudas da doença falciforme. Med (Ribeirao Preto Online). 43(3):231. https://www.researchgate.net/publication/274502850_Manejo_das_complicacoes_agudas_da_doenca_falciforme/fulltext/573929 2808ae9ace840d0ae8/Manejo-das-complicacoes-agudas-da-doenca-falciforme.pdf

Cançado, R. D., \& Jesus, J. A. (2007). A doença falciforme no Brasil. Rev Bras Hematol Hemoter. 29(3):204-6. https://www.scielo.br/scielo.php?script=sci_a rttext\&pid=S1516-84842007000300002

Carvalho, G. C., Araújo, J. L., Santos, G. T., Vieira, R. A., \& Ramos, C. C. B. S. R. (2020). Clinical and epidemiological profile of sickle cell anemia in children: an integrative review. Rev Eletrônica Acervo Saúde. 12(2):e2774. https://www.researchgate.net/publication/339420374_Clinical_and_epidemiol ogical_profile_of_sickle_cell_anemia_in_children_an_integrative_review

de Oliveira, M. M. S., Moura, M. A. M., Nascimento, M. E. B., Gois, M. S. A., Silva, P. J. C., \& Oliveira, H. F. (2020). Consequências da Anemia Falciforme em adolescentes: Uma revisão sistemática da literatura. Brazilian J Heal Rev. 3(4):10222-31. https://www.brazilianjournals.com/index.php/BJHR/article /view/14865\#: :text=A\%20literatura\%20aponta\%20que\%20as,com\%20o\%20passar\%20dos\%20anos

DeBaun, M. R., Jordan, L. C., King, A. A., Schatz, J., Vichinsky, E., Fox, C. K. et al. (2020). American Society of Hematology 2020 guidelines for sickle cell disease: Prevention, diagnosis, and treatment of cerebrovascular disease in children and adults. Blood Adv. 4(8):1554-88. https://pubmed.ncbi .nlm.nih.gov/32298430/

Domingos, I. F., Pereira-Martins, D. A., Sobreira, M. J. V. C., Oliveira, R. T. D., Alagbe, A. E., Lanaro, C. et al. (2020). High levels of proinflammatory cytokines IL-6 and IL-8 are associated with a poor clinical outcome in sickle cell anemia. Ann Hematol. 99(5):947 < https://pubmed.ncbi.nlm.nih.gov/32140892/

Edelstein, J. (1996). The sickled cell: from myths to molecules. Cambridge Harvard Univ Press.

Estrela, C. (2018). Metodologia Científica: Ciência, Ensino, Pesquisa. Editora Artes Médicas.

Felix, A. A., Souza, H. M., \& Ribeiro, S. B. F. (2010). Aspectos epidemiológicos e sociais da doença falciforme. Rev Bras Hematol Hemoter. 32(3):203-8. https://www.scielo.br/scielo.php?pid=S1516-84842010000300006\&script=sci_abstract\&tlng=pt

Fernandes, T. A. A de M., Medeiros, T. M. D de., Alves, J. J. P., Bezerra, C. M., Fernandes, J. V., Serafim, É. S. S. et al. (2015). Socioeconomic and demographic characteristics of sickle cell disease patients from a low-income region of northeastern Brazil. Rev Bras Hematol Hemoter. 37(3):172-7. https://www.scielo.b r/scielo.php?script=sci_arttext\&pid=S1516-84842015000300172

Furtado, A. N., Motta, J., \& Santos, M. D de D. (2015). Estudo do perfil dos pacientes portadores de Síndromes Falciformes acompanhados no Serviço de Hematologia do Centro Estadual de Hemoterapia e Hematologia do Espírito Santo (HEMOES). Rev Bras Pesqui em Saúde/Brazilian J Heal Res. 16(4):105-12. https://periodicos.ufes.br/rbps/article/view/11198

Ghafuri, D. L., Abdullahi, S. U., Jibir, B. W., Gambo, S., Bello-Manga, H., Haliru. L. et al. (2020). World Health Organization's Growth Reference Overestimates the Prevalence of Severe Malnutrition in Children with Sickle Cell Anemia in Africa. J Clin Med. 9(1):119. https://www.ncb i.nlm.nih.gov/pmc/articles/PMC7020064/

Gomes, R., Nascimento, E. F do., \& de Araújo, F. C. (2007). Por que os homens buscam menos os serviços de saúde do que as mulheres? As explicações de homens com baixa escolaridade e homens com ensino superior. Cad Saude Publica. 23(3):565-74. https://www.scielo.br/scielo.php?pid=S0102311X2007000300015\&script=sci_abstract\&tlng=pt 
Grosse, S. D., Odame, I., Atrash, H. K., Amendah, D. D., Piel, F. B., \& Williams, T. (2011). Sickle Cell Disease in Africa. 41(6):S398-3405. https://www.ncbi.nlm.nih.gov/pmc/articles/PMC3708126/\#: :text=Sickle\%20cell\%20disease\%20(SCD)\%20is,gene\%20mutation\%20(SS\%20disease).

Johnson, P. L., Lombardo, F. A., \& Moore, C. D. (2015). Options in the management of sickle cell disease. US Pharm. 40(7):4-7. https://www.uspharmacist. com/article/options-in-the-management-of-sickle-cell-disease\#: :text=Preventative\%20therapy\%20most \%20commonly\%20consists,option s\%20as\% 20the\%20disease\%20persists

Kassim, A. A., Pruthi, S., Day, M., Rodeghier, M., Gindville, M. C., Brodsky, M. A. et al. (2016). Silent cerebral infarcts and cerebral aneurysms are prevalent in adults with sickle cell anemia. Blood. 127(16):2038-40. https://pubmed.ncbi.nlm.nih.gov/26941400/

Kato, G. J., Piel, F. B., Reid, C. D., Gaston, M. H., Ohene-Frempong, K., Krishnamurti, L, et al. (2017) . Nature Reviews Disease Primer Sickle Cell Disease. https://www.researchgate.net/publication/330349462_NATURE_REVIEWS_DISEASE_PRIMERS_Collection_Includes_Sickle_Cell_Disease

Koche, J. C. (2011). Fundamentos de metodologia científica. Petrópolis: Vozes.

Leão, L. L., \& de Aguiar, M. J. B. (2008). Newborn screening: What pediatricians should know. J P ediatr (Rio J). 84(4 SUPPL.):80-90. https://www.scielo.br/pdf/jped/v84n4s0/v84n4s0a12.pdf

Lottenberg, R., \& Hassell, K. L. (2005). An evidence-based approach to the treatment of adults with sickle cell disease. Hematology Am Soc Hematol Educ Program. 58-65. https://pubmed.ncbi.nlm.nih.gov/16304360/

Loureiro, M. M., \& Rozenfeld, S. (2005). Epidemiology of sickle cell disease hospital admissions in Brazil. Rev Saude Publica. 39(6):943-9. https://www.scielo.br/scielo.php?script=sci_arttext\&pid=S1516-84842008000500015.

Ludke, M., André, M. E. D. A. (2013). Pesquisas em educação: uma abordagem qualitativa. São Paulo: E.P.U.

Magalhães, P.K. R., Turcato, M. F., Ângulo, I de L., \& Maciel, L. M. Z. (2009). Neonatal Screening Program at the University Hospital of the Ribeirao Preto School of Medicine, São Paulo University, Brazil. Cad Saude Publica. 25(2):445-54. https://www.scielo.br/scielo.php?script=sci_abstract\&pid=S0102311X2009000200023\&lng=en\&nrm=iso

McCavit, T. L., Lin, H., Zhang, S., Ahn, C., \& Quinn, C. T. F. G. (2011). Hospital volume, hospital teaching status, patient socioeconomic status, and outcomes in patients hospitalized with sickle cell disease. Am J Hematol. 86(4):377-80. https://pubmed.ncbi.nlm.nih.gov/21442644

Martins, M. M. F., \& Teixeira, M. C. P. (2017). Análise dos gastos das internações hospitalares por anemia falciforme no estado da Bahia. Cad Saúde Coletiva. 25(1):24-30. https://www.scielo.br/scielo.php?pid=S1414-462X2017000100024\&script=sci_abstract\&tlng=pt

Martins, P. R. J., Moraes-Souza, H., Silveira, T. B. (2010). Morbimortalidade em doença falciforme. Rev Bras Hematol Hemoter. 32(5):378-83. https://www.s cielo.br/scielo.php?pid=S1516-84842010000500010\&script=sci_abstract\&tlng=pt

Marques, L. N., Souza, A. C. A, Pereira, A. R. (2015). O viver com a doença falciforme: percepção de adolescentes. Rev Ter Ocup Univ São Paulo. 26(1):10917. https://www.revistas.usp.br/rto/article/download/52376/96500

Menezes, A. S. O. P, Len, C. A., Hilário, M. O. E., Terreri, M. T. R. A, Braga, J. A. P. (2013). Qualidade de vida em portadores de doença falciforme. Rev Paul Pediatr. 31(1):24-9. https://www.scielo.br/scielo.php?script=sci_arttext\&pid=S0103-05822013000100005

Moerdler, S., Manwani, D. (2018). New insights into the pathophysiology and development of novel therapies for sickle cell disease.

Hematol (United States). 493-506. https://pubmed.ncbi.nlm.nih.gov/30504350/

Paiva e Silva, R. B de., Ramalho, A. S., Cassorla, R. M. (1993). Sickle cell disease as a public health problem in Brazil. Rev Saude Publica. 1993;27(1):548. https://www.scielo.br/scielo.php?script=sci_abstract\&pid=S0034-89101993000100009\&lng=pt\&nrm=iso\&tlng=en

Palermo, T. M., Drotar, D., McGowan, K. (2002). Parental Report of Health-Related Quality of Life in Children with Sickle Cell Disease. J Behav Med. 25(3):269-83. https://link.springer.com/article/10.1023/A:1015332828213

Pereira A. S. et al. (2018). Metodologia da pesquisa científica. UFSM

Pereira, S. A. S., Cardoso, C. S., Brener, S., Proietti, A. B. F. C. (2008). Doença falciforme e qualidade de vida: Um estudo da percepção subjetiva dos pacientes da Fundação Hemominas, Minas Gerais, Brasil. Rev Bras Hematol Hemoter. 30(5):411-6. https://www.scielo.br/scielo.php?script=sci_arttext\&pid=S151684842008000500015

Piel, F. B., Hay, S. I., Gupta, S., Weatherall, D. J., Williams, T. N. (2013). Global Burden of Sickle Cell Anaemia in Children under Five, 2010-2050: Modelling Based on Demographics, Excess Mortality, and Interventions. PLoS Med. 10(7). https://pubmed.ncbi.nlm.nih.gov/23874164/

Salvador. (2019). Secretaria de Municipal de Saúde. <http://www.saude.salvador.ba.gov.br/.>.

Soares, E. P. B., da Silva, D. S., Xavier, A. S. G., Carvalho, E. S. de S., Cordeiro, R. C., Araújo, E. M de. (2014). Cuidar de pessoas com doença falciforme na unidade de emergência: discurso de uma equipe multiprofissional. Ciência, Cuid e Saúde. 13(2):278-85. https://www.researchgate.net/publication/26438 4714_Cuidar_de_pessoas_com_doenca_falciforme_na_unidade_de_emergencia_discurso_de_uma_equipe_multiprofissional

Thein, S. L. H. J. (2018). How I treat the older adult with sickle cell disease. Blood. 132(17):1750-60. https://ashpublications.org/blood/article/1 32/17/1750/39513/How-I-treat-the-older-adult-with-sickle-cell

UFRGS. (2020). Universidade Federal do Rio Grande do Sul. Faculdade de Medicina. Programa de Pós-Graduação em Epidemiologia, Telessaúde UFRGS. https://www.ufrgs.br/telessauders/

Williams, T. N., Uyoga, S., Macharia, A., Ndila, C., McAuley, C. F., Opi, D. H., et al. (2009). Bacteraemia in Kenyan children with sickle-cell anaemia: a retrospective cohort and case-control study. Lancet. 374(9698):1364-70. https://www.thelancet.com/journals/lancet/article/PIIS0140-6736(09)61374-X/fulltext 
Research, Society and Development, v. 10, n. 7, e22510716510, 2021

(CC BY 4.0) | ISSN 2525-3409 | DOI: http://dx.doi.org/10.33448/rsd-v10i7.16510

Yin, R. K. (2015). O estudo de caso. Bookman

Zago, M. A., Pinto, A. C. S. (2007). Fisiopatologia das doenças falciformes: Da mutação genética à insuficiência de múltiplos órgãos. Rev Bras Hematol Hemoter. 29(3):207-14. https://www.scielo.br/scielo.php?pid=S1516-84842007000300003\&script=sci_abstract\&tlng=pt 